\title{
ENTRE FLUXOS E ESCALAS: COVID-19 E SUAS IMPLICAÇÕES NA REDE DE TRANSPORTE AÉREO NO PRIMEIRO SEMESTRE DE 2020
}

\author{
Bruno Carneiro de Oliveira* \\ Universidade Federal de Goiás
}

\author{
Denis Castilho** \\ Universidade Federal de Goiás
}

\begin{abstract}
Resumo: A crise sanitária ocasionada pela Covid-19 tem demonstrado que o novo coronavírus não acomete apenas as vias mais distantes do pulmão humano, mas também os fluxos da economia mundializada. Neste artigo analisamos as consequências do novo coronavírus na rede de transporte aéreo no primeiro semestre de 2020 a partir de uma abordagem multiescalar. Os procedimentos metodológicos basearam-se em coleta de dados do fluxo de transporte aéreo e de informações referentes a casos de Covid-19 em localidades selecionadas. As principais bases de dados utilizadas foram a Agência Nacional de Aviação Civil (ANAC), a International Civil Aviation Organization (ICAO), a Organização Mundial da Saúde (OMS) e relatórios de concessionárias de aeroportos. A análise leva a refletir sobre a dependência das corporações, especialmente de grandes companhias aéreas, às ações do Estado e revela um sistema de espoliação (e de pilhagem) ainda mais agressivo e articulado em tempos de crise como essa ocasionada e/ou agravada pela Covid-19.
\end{abstract}

Palavras-chave: Covid-19. Transporte aéreo. Fluidez. Crise econômica.

\section{THROUGH THE FLOWS AND THE SCALES: COVID-19 AND ITS IMPLICATIONS FOR THE AIR TRANSPORTATION NETWORK IN THE 1ST SEMESTER OF 2020}

Abstract: The health crisis caused by Covid-19 has shown that the new coronavirus affects not only the most distant pathways of the human lung but also the flows of the globalized economy. In this paper, we analyze the consequences of the new coronavirus on the air transportation network in the 1 st semester of 2020 in a multiscale approach. The methodological procedures were based on the gathering of air transportation flow data and information related to Covid-19 cases in selected locations. The main databases were the National Civil Aviation Agency (ANAC), the International Civil Aviation Organization (ICAO), the World Health Organization (WHO), and reports from highway and airport concessionaires. The analysis leads to reflect on the dependence of corporations, especially large airlines, on the actions of the State and reveals a system of exploitation (and looting) even more aggressive and articulated in times of crisis such as that caused and/or aggravated by COVID - 19 .

Keywords: Covid-19. Air Transportation. Fluidity. Economic crisis.

\section{ENTRE FLUJOS Y ESCALAS: COVID-19 Y SUS IMPLICACIONES EN LA RED DE TRANSPORTE AÉREO EN EL PRIMER SEMESTRE DE 2020}

Resumen: La crisis sanitaria derivada de la Covid-19 ha demostrado que el nuevo coronavirus no solo afecta a las vías más distantes del pulmón humano, sino también a los flujos de la economía globalizada. En este artículo analizamos las consecuencias del nuevo coronavirus en la red de transporte aéreo en el primer semestre de 2020 desde un enfoque multiescalar. Los procedimientos metodológicos se basaron en la recopilación de datos de flujo de transporte aéreo y de información relacionada con los casos de Covid-19 en ubicaciones seleccionadas. Las principales bases de datos utilizadas fueron la Agencia Nacional de Aviación Civil de Brasil (ANAC), la International Civil Aviation Organization (ICAO), la Organización Mundial de la Salud (OMS) y los informes de las concesionarias de aeropuertos. El análisis lleva a reflexionar sobre la dependencia de las corporaciones, especialmente las grandes aerolíneas, a las acciones del Estado y revela un sistema de saqueo aún más agresivo y articulado en tiempos de crisis como esta provocada y/o agravada por el nuevo coronavirus.

Palabras clave: Covid-19. Transporte aéreo. Fluidez. Crisis económica.

*Mestre e Doutorando em Geografia pela Universidade Federal de Goiás. Endereço: Av. Esperança, s/n - Samambaia, Goiânia - G0, 74001-970. Orcid: https://orcid.org/00000003-3035-6174. E-mail: bcarneirodeoliveira@gmail.com.

** Doutor em Geografia pela Universidade Federal de Goiás, onde é professor do Instituto de Estudos Socioambientais nos cursos de graduação e pós-graduação. Endereço: Av. Esperança, s/n - Samambaia, Goiânia - G0, 74001-970. Orcid: https://orcid.org/0000-0002-2467-1189. E-mail: deniscastilho@hotmail.com. 
Introdução

O fluxo de pessoas e de mercadorias guarda especial relação com a implementação e inovação de redes técnicas. A obsessão de grupos econômicos em torno da constante evolução dos fluxos, contudo, tem sido colocada em questão diante das implicações que a pandemia da Covid-19 tem causado nos sistemas de circulação.

Embora a doença tenha intrigado a comunidade científica mundial pela forma como ataca seres humanos de genótipos diferentes e pelo modo como o vírus se espalha pelos lugares, não se trata exatamente de uma novidade como tem aparentado ser. Em ensaio publicado na revista estadunidense Time, Harari (2020) comenta que as epidemias já acometiam milhões de pessoas muito antes do momento atual da globalização, em épocas como no século XIV quando houve a peste negra onde não havia cruzeiros ou aviões e outros exemplos, como a varíola que, em 1520, por meio de um hospedeiro oriundo da Europa, matou cerca de um terço da população onde atualmente fica o território mexicano. Esses fatos mostram que as pandemias não são recentes. Ocorre que agora a sua geograficidade possui nuances peculiares, dentre as quais destacamos a natureza quase perfeita do vírus para uma multiplicação e expansão a nível mundial em um curto espaço de tempo e sua forte relação com as redes.

A questão ambiental em torno do surgimento do vírus, somada a um mundo cada vez mais fluído, também denota a emergência de novas pandemias em intervalos de tempo cada vez menores. Fato é que, sendo os seres humanos os principais vetores do espraiamento do vírus, as redes de transportes se constituem como vetores potencializadores pelas escalas e fluxos que alcançam. Na escala mundial, portanto, é o transporte aéreo, por excelência, o principal vetor potencializador da pandemia.

Em vista disso, o presente artigo busca analisar os fluxos decorrentes do transporte aéreo e sua correlação com a pandemia da Covid-19 a nível mundial e no Brasil com foco posterior nas unidades federativas do Distrito Federal e Goiás. O recorte temporal é majoritariamente o primeiro semestre de 2020 e, para efeitos de comparação, o mesmo período do ano anterior.

A metodologia baseou-se em revisão bibliográfica sobre redes técnicas e sua relação com a escala e análise de dados, de fontes jornalísticas e de dados referentes ao fluxo de transporte aéreo, rodoviário e mobilidade urbana em localidades selecionadas. Foram coletados e analisados dados referentes a casos de Covid-19 nos recortes selecionados. Utilizamos dados e informações disponíveis em sites de Aeroportos Nacionais, da Organização Internacional de Aviação Civil (ICAO), da Agência Nacional de Aviação Civil (ANAC), do portal de movimentação de aeronaves em tempo real FlightRadar24, do Instituto Brasileiro de Geografia e Estatística (IBGE), de fontes jornalísticas, de relatórios de concessionárias de aeroportos, da plataforma de monitoramento da Covid-19 da Universidade Johns Hopkins e da Organização Mundial da Saúde (OMS).

Entre fluxos e escalas: o rearranjo das redes em tempos e espaços de crises

As redes, com suas linhas e nós, articuladas e comandadas por ações, alimentam os fluxos, as conexões e compõem uma estrutura multiescalar. Santos (1988) argumenta que o espaço é formado por fixos e fluxos, havendo fluxos que se originam dos fixos e fluxos que chegam aos fixos. Os fixos configuram-se como as forças produtivas (instrumentos e trabalhadores) enquanto os fluxos são o movimento e a circulação. Para o autor, o espaço pode ser percebido como um "teatro de fluxos com diferentes níveis, intensidades e orientações" (SANTOS, 1997, p. 25), permeado tanto por fluxos hegemônicos e hegemonizados, quanto por fluxos rápidos e lentos.

Há uma preferência das grandes corporações, segundo Santos (2006), por espaços reticulados e incrementados por elementos preparados para atender as demandas de produção e criação de novos fixos para novos fluxos. As redes, nesse sentido, são cada vez mais globais, sendo que sua compreensão seria prejudicada caso fossem consideradas apenas a nível local ou regional. Diante desse contexto, a globalização, como estágio emblemático da internacionalização, conduz a um aumento da circulação e da comunicação, responsáveis por novas hierarquias e especialização que impactam diferentes escalas de modos distintos.

Na concepção de Raffestin (1993), o território aparece como um produto do espaço em que há energia e informação e possui relações marcadas, as quais o autor busca vincular às ações de diferentes atores em relação às redes. Para o autor, o que determina os grupos ou indivíduos que ocuparão determinados pontos no espaço é a distância que pode ser de caráter espaço-temporal, a qual poderá permitir as interações e circulações entre diferentes lugares. As interações de ordem política, social ou econômica permitem a criação de malhas, nós e redes que moldam o sistema territorial enfatizado pelo autor para garantir o controle sobre a distribuição de matéria-prima e produtos, além da integração e coesão de territórios. Desse modo, 
conforme salienta Santos (2006), o poder não pode estar desvinculado da existência das redes, pois a divisão territorial do trabalho resultante desse processo privilegia determinados grupos e territórios.

Nesse ínterim, o lugar situa-se como nó da tessitura que compõem os territórios. Santos (2006, p. 182) explica que lugar é onde "os fragmentos da rede ganham uma dimensão única e socialmente concreta, graças a ocorrência, na contiguidade, de fenômenos sociais agregados, baseados num acontecer solidário, que é fruto da diversidade". O autor propõe, ainda, que as redes se figuram como um "veículo de um movimento dialético", ora opondo território e lugar e ora os colocando em complementaridade. São nos lugares que estão os atores, os centros de comando, onde estão instalados os fixos e de onde partem os fluxos. Costa e Ueda (2007) também argumentam sobre a importância de se pensar o território em suas múltiplas dimensões nos estudos sobre redes técnicas para não considerar a técnica como único meio de transformação dos territórios, sendo este um espaço apropriado por grupos e suporte humano. De acordo com Parente (2001):

As redes tornaram-se ao mesmo tempo uma espécie de paradigma e de personagem principal das mudanças em curso justo no momento em que as tecnologias de comunicação e de informação passaram a exercer um papel estruturante na nova ordem mundial (...). Nada parece escapar às redes, nem mesmo o espaço, o tempo e a subjetividade. (PARENTE, 2001, p. 101)

Perante arranjos territoriais marcados pelas redes, Silva Junior (2007) aponta que os lugares acabam se tornando nós que intercalam fluxos de informações e de capital de diversas ordens cada vez mais velozes e intensos. O lugar, explica Carlos (2007), configurase como ponto de articulação entre um global em construção e um local enquanto materialidade, sendo o palco da manifestação de desequilíbrios, conflitos e tendências da sociedade que irradiam para o nível global.

As ações que animam as redes, conforme assinalam Offner e Pumain (apud Silveira, 2003), são delineadas para promover a circulação, unindo e solidarizando os territórios, mas do mesmo modo também opondo as lógicas institucionais e funcionais. Como observado por Castilho (2019, p. 296), embora alguns dos efeitos das redes sejam diluídos no cotidiano para garantir o consumo e assegurar as funções do poder, a "fluidez em face do controle é específica a determinados grupos, por isso seletiva". Isso significa que as redes também são, conforme conclui o autor, vetores de restrições e de espoliação. Elas tanto liberam como aprisionam, explica Raffestin (1993) - são elementos inacabados, podendo se adaptar conforme as variações e mudanças no tempo e no espaço.

Essa adaptabilidade das redes também ocorre como resposta a tempos e espaços de crises. No caso da pandemia, embora seus impactos em companhias aéreas e na própria economia mundial ainda sejam imensuráveis, as implicações nos fluxos aéreos internacionais são indiscutíveis. Frente a isso, o modo como as companhias acionam os Estados revela uma dependência geralmente camuflada pelos arautos do neoliberalismo. Mas é justamente nesse processo de rearranjo e de adaptação às crises que uma característica das redes se escancara. Trata-se das tramas espoliativas, as quais se adensam pelo modo como as corporações acionam os recursos públicos.

No que tange à crise econômica alargada pela pandemia da Covid-19, é importante reiterar que os principais vetores de difusão do vírus são as pessoas. 0 transporte aéreo, nesse sentido, pode ser visto como um vetor potencializador de alcance mundial, assim como ocorreu com outras epidemias no leste asiático nos anos 2000 com o Sars e o Mers. Na perspectiva geográfica, é possível dizer que a pandemia revelou ainda mais disparidades no que tange às redes, principalmente a rede de transportes, vetor de mobilidade e de fluxos. Diversas reportagens jornalísticas nos primeiros meses do ano de 2020 apontaram a diminuição da mobilidade em suas diversas modalidades - no âmbito local, no caso do trânsito de veículos e pedestres; no escopo regional, em que é possível mencionar o transporte rodoviário; e a nível multiescalar e internacional, quando se trata do transporte aéreo que depende sempre de fixos locais para alimentar os fluxos globais.

No caso do território brasileiro, foi registrada forte queda no fluxo rodoviário e aéreo em março, logo após o primeiro mês em que foram registrados os primeiros casos da doença. No caso das rodovias sob concessão, o Índice ABCR ${ }^{1}$ demonstrou no mês de abril de 2020 uma queda de $36,7 \%$ de fluxo de veículos leves e de $19,1 \%$ de fluxo de veículos pesados em relação a março do mesmo ano. Em relação ao mesmo período no ano de 2019 , essa queda foi de $51,5 \%$ para veículos leves e $20,5 \%$ para veículos pesados. A título de exemplo, no Distrito Federal a queda do tráfego de veículos foi de $45 \%$ no mês de março de 2020 com relação ao mesmo período do ano anterior, aumentando nos meses de abril e maio para $38,56 \%$ e $31,26 \%$, respectivamente, de acordo com nota do Departamento de Estradas e Rodagens da unidade

10 índice $A B C R$ é calculado com base no fluxo total de veículos que passa pelas praças pedagiadas. O número índice, cuja base média de $1999=100$, fo construído com informações de fluxo de pedágio de 33 concessionárias e é composto atualmente pelas informações das praças de 51 concessionárias. Desde 2012 o IBGE incorpora o índice ao cálculo do Produto Interno Bruto. Mais informações disponíveis em: <https://abcr.org.br/indice/entend-ao-indice>. 
federativa em junho de 2020.

A flexibilização de medidas preventivas, no entanto, fez com que o mês de maio registrasse alta no fluxo do transporte rodoviário. Isso foi desencadeado sobretudo pelos atritos entre atribuições dos governos federal, estadual e municipal no enfrentamento da pandemia. As repetidas vezes em que o governo federal minimizou a gravidade da pandemia, ajuda a entender sua prioridade à pauta econômica e ao peso que commodities como a soja exerce na balança comercial do país. "Agro aquece mercado de caminhões - 0 novo coronavírus derrubou a economia e a atividade de transporte, mas não as relacionadas ao agronegócio, segmento que vive momento positivo". Essa manchete da reportagem do jornal Estadão de 26 de maio de 2020 fornece pistas sobre os motivos que não levaram o fluxo de veículos pesados diminuir mesmo diante de uma pandemia.

Isso revela a pouca eficiência das primeiras decisões adotadas e deixa a saúde pública em situação ainda mais vulnerável, sobretudo da classe trabalhadora, justo no período de aumento significativo no número de óbitos. No dia 22 de julho, por exemplo, o país registrou recorde de casos, somando, em um único dia, mais de 65 mil novos casos e 1.293 mortes. No mês de setembro já somava mais de 4 milhões de casos. Os dados são de um consórcio de veículos de imprensa como resposta às atitudes do governo federal em ter retirado informações do ar, atrasado divulgação de boletins sobre a doença e ameaçado sonegar informações do Ministério da Saúde $(\mathrm{G} 1,2020)$.

Esse fato revela um problema que antecede e que transcende a própria pandemia. Ela, contudo, não deixa de suscitar lições que traduzem uma doença que tomou conta do país e que pode conduzi-lo a uma situação de aumento dos artifícios de controle que indiscutivelmente também se reverberam na circulação e nos fluxos. A deliberada irresponsabilidade do governo federal frente a pandemia, portanto, revela suas prioridades e também ajuda a entender o modo como os grupos que controlam as redes de transportes se rearranjam à crise. Esse rearranjo acontece especialmente no nível político. 0 caso do transporte aéreo é ainda mais peculiar pela escala que alcança e será analisado nas próximas seções.

Pandemia e suas implicações no transporte aéreo: um caso peculiar

A rede de transporte aéreo é ampla e envolve diversos setores da economia que alimentam o fluxo de passageiros e de carga. No que se refere ao transporte de passageiros, a pandemia da Covid-19 fez com que a circulação de pessoas articulada pela aviação fosse bastante afetada. 0 que não é possível circular pelas redes de comunicação fica também inviável de ser realizado pelo sistema de transportes se o objetivo for cumprir um radical distanciamento social. 0 turismo, em sua ampla gama de modalidades, é um desses setores profundamente afetados. São diversas as localidades que dependem da atividade turística como meio de renda para seus habitantes e como arrecadação de receita para custeio público que são obrigados (ou simplesmente tem a noção) em optar pela vida, bloqueando fluxos financeiros, de pessoas, resguardando seus equipamentos e insumos de saúde.

No âmbito global, entre os dias 30 de dezembro de 2019 e 30 de junho de 2020, a média do fluxo semanal de voos caiu $86,37 \%$ em todo o mundo, como é possível visualizar na Figura 1. A Figura 2 também é bastante ilustrativa, pois já no mês de abril de 2020 o monitoramento de aeronaves sobrevoando a França registrava queda de $92,4 \%$ em relação ao mesmo mês do ano anterior.

Figura 1 - Mundo - número de voos diários (em laranja), média de voos diários (em cinza) e casos de Covid-19 ao longo do tempo (em vermelho) entre 30 de dezembro de 2019 e 30 de junho de 2020

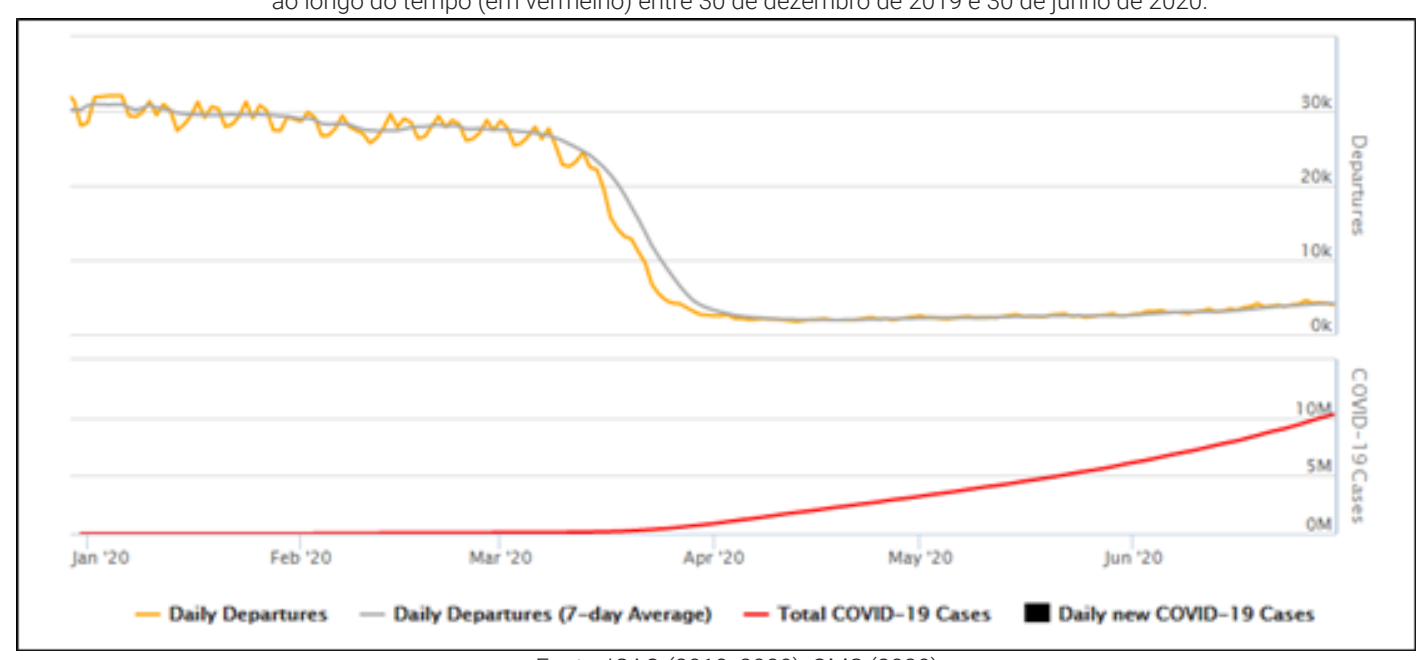

Fonte: ICAO $(2019,2020)$; OMS (2020). 


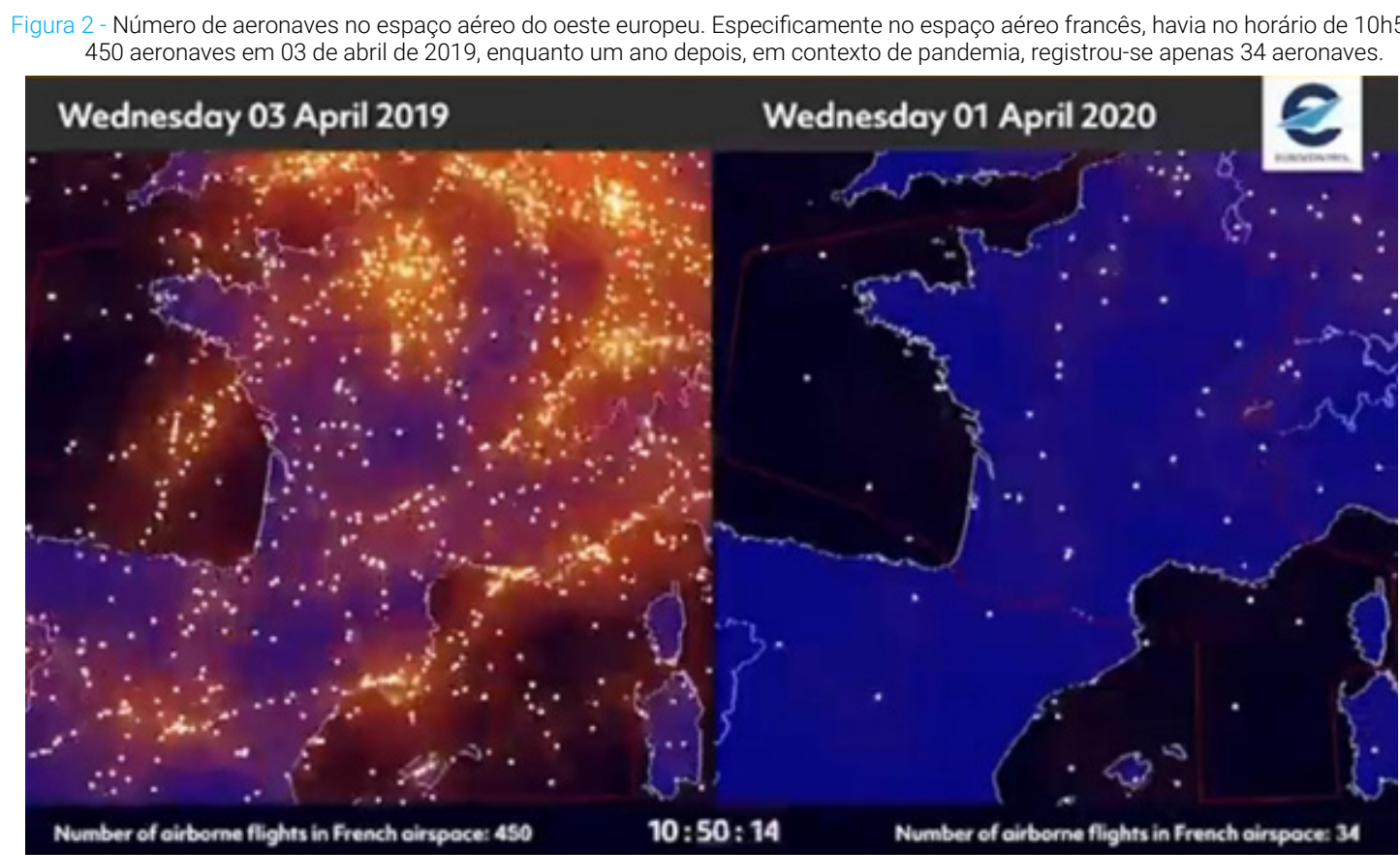

Fonte: Eurocontrol (2020).

De acordo com a Organização Mundial da Saúde (OMS, 2020), os primeiros casos surgiram na China em 31 de janeiro de 2019 a partir da identificação de um novo tipo de corona vírus denominado Sars-Cov2. Em 13 de janeiro foi confirmado o primeiro caso de contaminação na Tailândia, o primeiro fora da China. Em 30 de janeiro, a OMS reportou 7.818 casos no mundo todo, sendo a maior parte na China e mais 82 casos presentes em outros 18 países. A evolução da quantidade de casos em breve período de dias dava sinais da velocidade em que o vírus se espalha. No dia 11 de março a Covid-19 foi caracterizada como pandemia devido aos "níveis alarmantes de espraiamento, severidade e inalação" (OMS, 2020).
Diante desse quadro de avanço global do vírus, a OMS junto à Organização Internacional de Aviação Civil (ICAO) elaboraram recomendações para orientar o funcionamento do transporte aéreo no contexto da pandemia, incluindo fechamento de fronteiras aéreas e diminuição do fluxo de passageiros atendendo recomendações de distanciamento dentro das aeronaves. Experiências nesse sentido já haviam acontecido anteriormente com a Sars (2003), Gripe Asiática (2005 e 2013) e Mers (2015) e foram incorporadas para a gestão de enfretamento da Covid-19 a nível global. A Figura 3 demonstra a evolução do número de casos em países selecionados.

Figura 3 - Número de casos de Covid-19 confirmados ao longo do tempo em países selecionados.

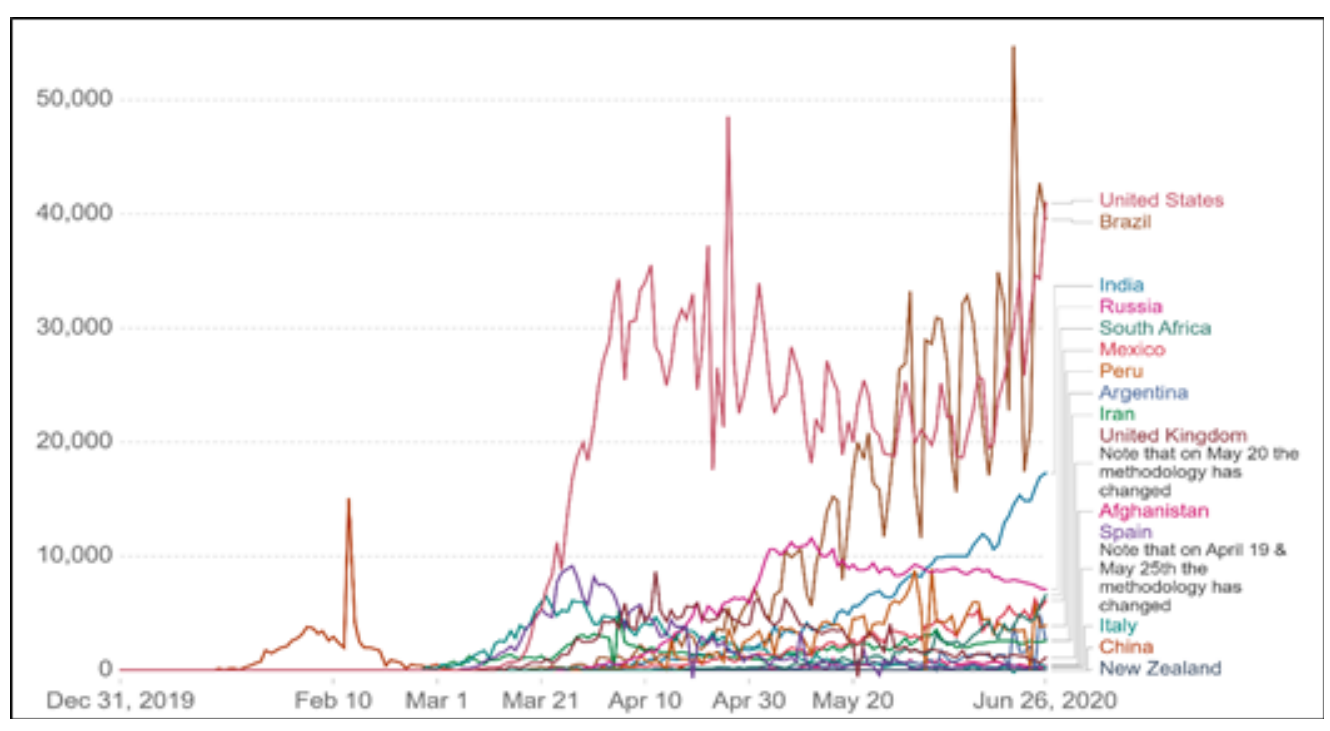

Fonte: Roser et. al, 2020. Disponível em: <https://ourworldindata.org/coronavirus> 
As medidas relativas ao distanciamento social, diminuição de fluxo de pessoas, bloqueio de fronteiras entre outras medidas sanitárias fizeram com que muitos países chegassem ao pico de casos fazendo com que o fluxo normal de pessoas fosse retomado em etapas na escala local. A Figura 3 demonstra o número de casos de Covid-19 em diversos países, entretanto o transporte aéreo, continua estagnado com relação aos meses anteriores à pandemia como é possível verificar no exemplo da América do Sul na Figura 4.

Figura 4 - América do Sul - número de voos diários (em laranja), média de voos diários (em cinza) e casos de Covid-19 ao longo do tempo (em vermelho) entre 30 de dezembro de 2019 e 30 de junho de 2020.

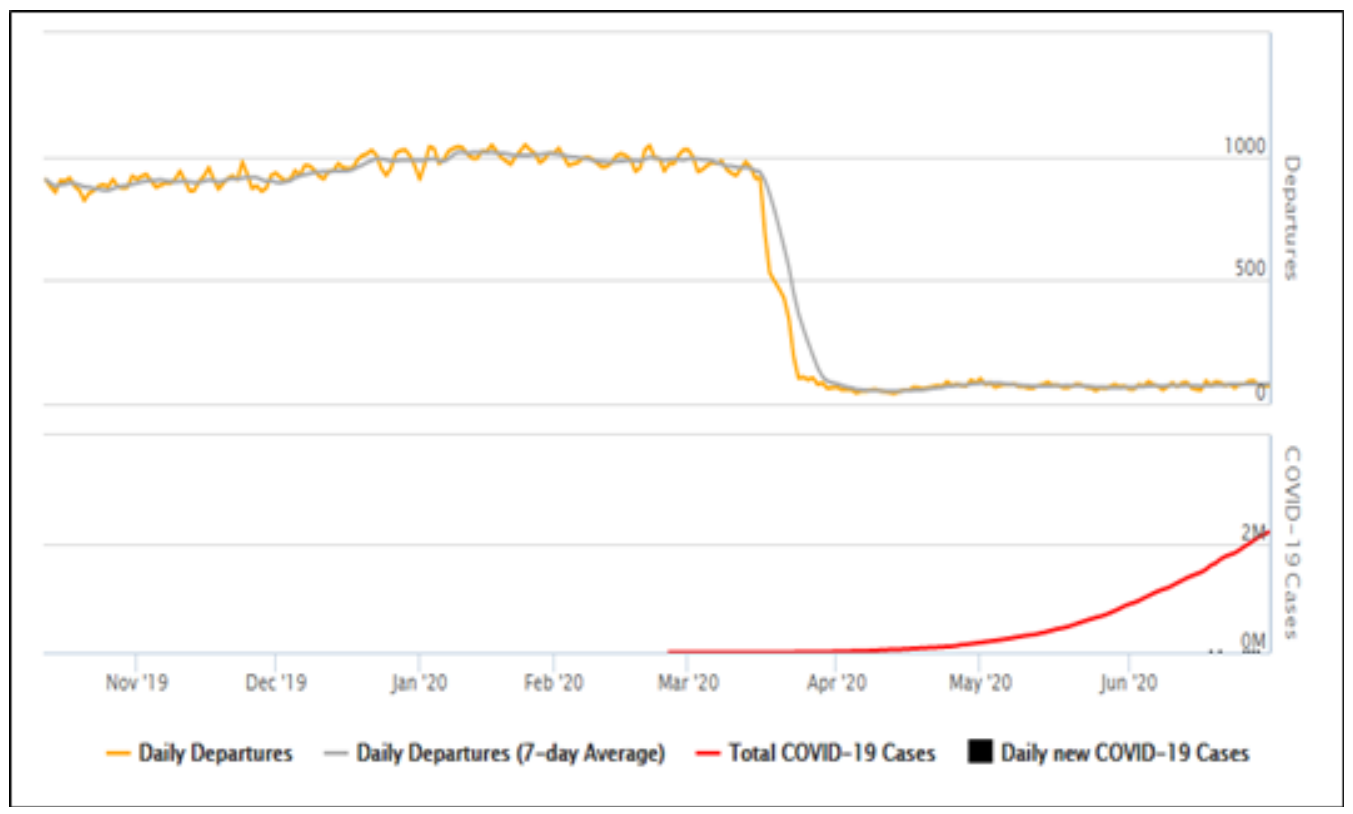

Fonte: ICAO (2019, 2020); OMS (2020).

Os meses de março e abril foram decisivos para os países da América do Sul que tiveram o número de voos em queda vertiginosa e o aumento do número de casos de Covid-19 em franca escalada. Para se ter uma ideia, antes da qualificação de pandemia a média semanal do número de voos na região em 1 de março era de 991, enquanto em 1 de abril foi de 81 voos, representando uma queda de $91,83 \%$ e tem se estagnado desde então. Em função disso, a Associação Internacional de Transporte Aéreo prevê prejuízos à conectividade da América Latina com o restante do mundo. No final de maio, o grupo Latam e suas afiliadas no Chile, Peru, Equador, Colômbia e nos Estados Unidos entraram com pedido de recuperação judicial nos Estados Unidos, medida similar à adotada semana antes pela Avianca (HOLTZ, 2020).

No que tange ao avanço da pandemia na América do Sul, o Brasil possui $62,94 \%$ do número de casos (mês de referência: junho) de acordo com dados do projeto Worldmeters ${ }^{2}$. O Chile possuía 14.615 casos

2 Worldmeter é um agregador independente de estatísticas globais com o objetivo de tornar as estatísticas mundiais acessíveis ao público em tempo real feito por desenvolvedores, pesquisadores e voluntários em todo o mundo com sede nos Estados Unidos. É utilizado por diversas instituições pelo mundo como o governo do Reino Unido, Universidade Johns Hopkins e jornal The New York Times. Com a pandemia da Covid-19, o website tem uma seção exclusiva para o tema em que agrega dados a partir de relatórios oficiais dos governos e informações apuradas pelas mídias locais pelo mundo. e 298 mortes, ambos por milhão de habitantes, sendo as maiores taxas da região. 0 Brasil, figura-se entre os cinco primeiros países nesses rankings e é visto como epicentro da epidemia por diversos fatores, os quais estão discutidos na seção seguinte.

\section{0 transporte aéreo civil no brasil frente à pandemia da covid-19}

No Brasil, a Agência Nacional de Aviação Civil (ANAC) responsável pela regulação e fiscalização das atividades, infraestrutura e aeroportos brasileiros implementou uma série de recomendações sanitárias em consonância com a Agência Nacional de Vigilância Sanitária (Anvisa), Ministério da Saúde (MS) e OMS. Nos aeroportos, as orientações da OMS foram seguidas com relação aos passageiros oriundos do exterior com orientações e intensificação da vigilância em casos suspeitos de Covid-19. Para os trabalhadores aeroportuários, são observadas a necessidade de distância de comunicação presencial com os passageiros, maior frequência de avisos sonoros em relação à pandemia, uso intensivo dos equipamentos de proteção individual (EPIs) e adoção da "etiqueta respiratória", orientando a maior higienização de mãos, cuidados com tosse, espirros, 
uso de máscaras de proteção etc. Todas as orientações podem ser conferidas na cartilha "Protocolos sanitários para as operações no setor de aviação civil em período de pandemias" disponibilizada pela ANAC (2020).

A Figura 5 representa o número de decolagens no Brasil entre os meses de janeiro e maio dos anos de
2019 e 2020. Entre os meses de março e abril houve a maior queda do número de decolagens no ano de $2020,-86,13 \%$, causada pelas medidas de contenção ao avanço da pandemia. Em relação ao mês de abril do ano anterior, houve queda de praticamente $90 \%$ no número de decolagens de acordo com a ANAC $(2019,2020)$.

Figura 5 - Número de decolagens entre janeiro e maio dos anos de 2019 e 2020.

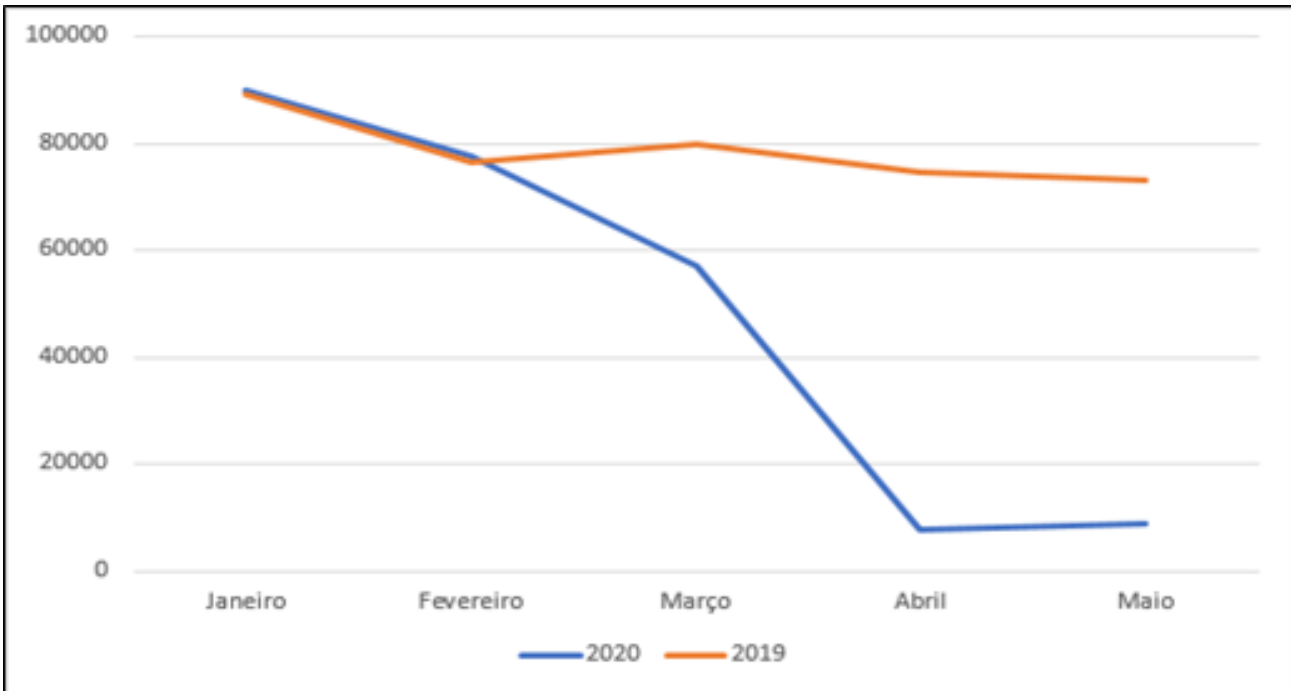

Fonte: ANAC $(2019,2020)$

Em consonância com esses dados, reportagem da Folha de São Paulo do mês de abril apurou a redução de $90 \%$ da oferta de voos das três principais empresas aéreas do Brasil (Gol, Latam e Azul), o que implicou em demissões, suspensões de contratos ou redução de salários de funcionários, diminuição do número de rotas domésticas, suspensão de maior parte dos voos internacionais e aeronaves inativas. A Azul, por exemplo, possuía de suas 153 aeronaves 114 paradas. Essas razões têm feito as empresas buscarem apoio emergencial junto ao Banco Nacional de Desenvolvimento Econômico e Social, similar ao que tem acontecido em outros países, nos quais companhias aéreas têm recorrido ao Estado para conter os prejuízos decorrentes da pandemia. Nesse ínterim a pandemia tem se agravado no país como demonstram as Figuras 6 e 7.

Figura 6 - Número de casos de Covid-19 ao longo do tempo no Brasil.

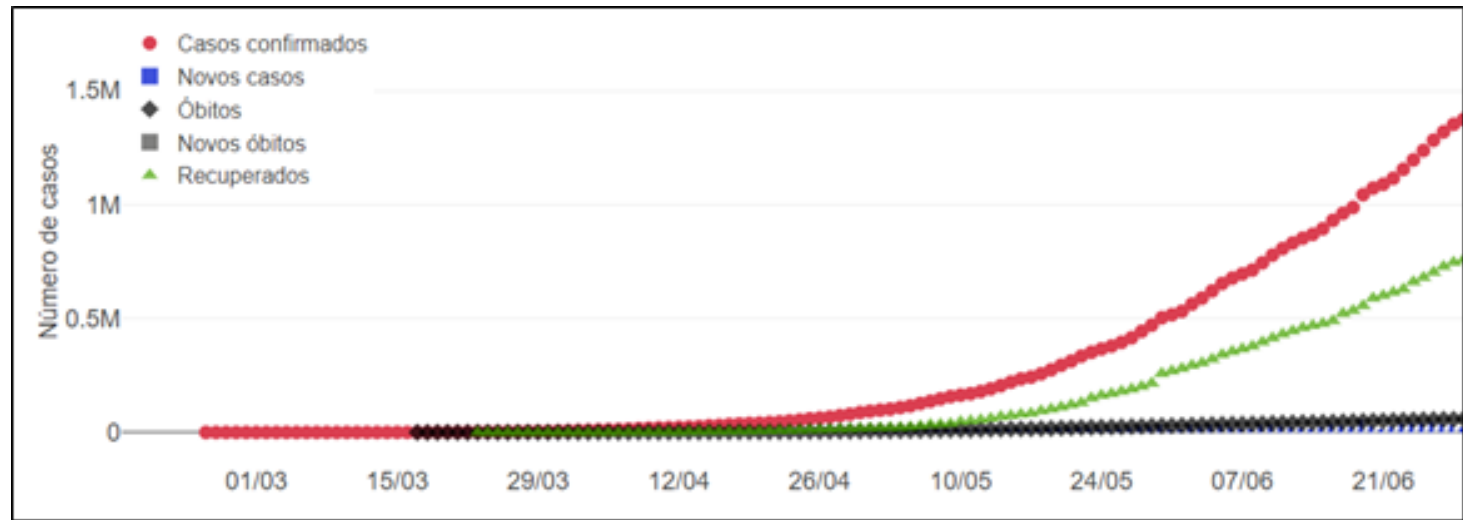




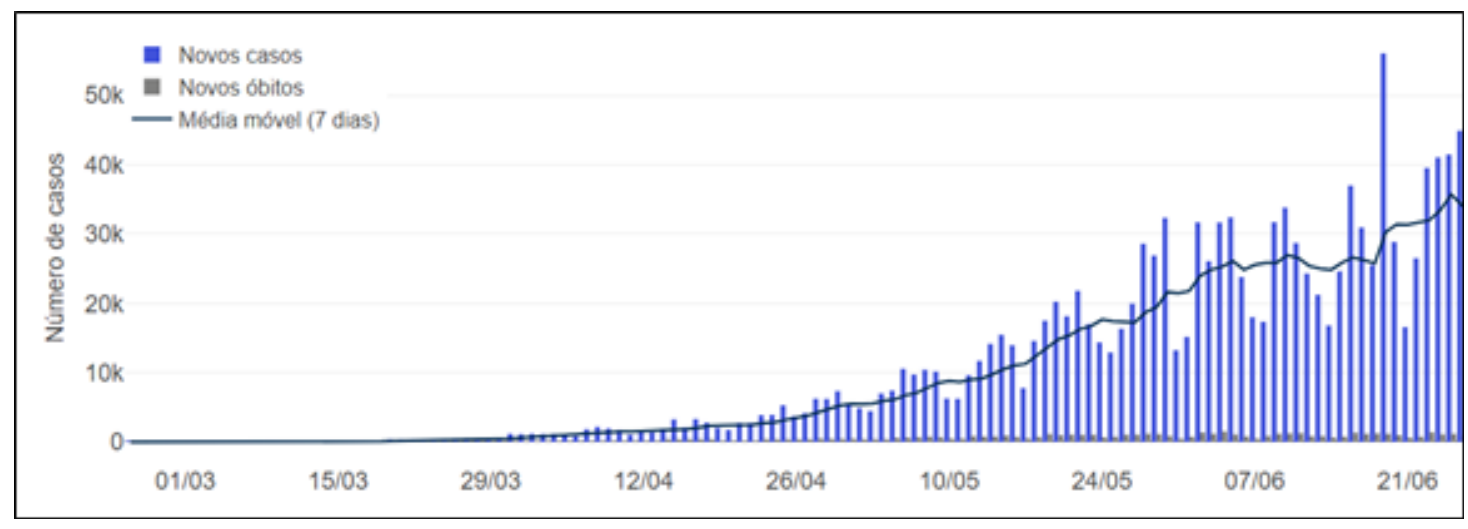

Fonte: COTA (2020).

Uma das razões para o crescente número de casos no Brasil e uma certa estabilização do número de casos diários é decorrente do decréscimo do índice isolamento social ${ }^{3}$, de acordo com a base de dados da consultoria In Loco $^{4}$.

3 Uma publicação de Wilder-Smith e Freedman (2020) delineia as diferenças entre os termos distanciamento social, isolamento e quarentena. 0 distanciamento social é "realizado para reduzir as interações entre pessoas em uma comunidade mais ampla, na qual os indivíduos podem ser infecciosos, mas que ainda não foram identificados e, portanto, ainda não isolados. Como as doenças transmitidas por gotículas respiratórias exigem certa proximidade das pessoas, o distanciamento social das pessoas reduzirá a transmissão". Essa definição, apesar das denominações diferentes, vai de encontro ao proposto no índice de isolamento social abordado. A Universidade Federal do Rio Grande do Sul (UFRGS) também elaborou um breve texto didático e acessivel sobre essas diferenças. Mais informações podem ser conferidas em: <https://www.ufrgs. br/telessauders/posts_coronavirus/qual-a-diferenca-de-distanciamento-socialisolamento-e-quarentena/>.

4A consultoria InLoco trabalha com tecnologia de localização precisa entregando uma tecnologia 30 vezes mais precisa que a do GPS. A empresa brasileira elaborou o Índice de Isolamento Social para contribuir no combate à disseminação da Covid-19 com o objetivo único de fornecer dados cada vez mais precisos para o poder público e institutos de pesquisa. Mais informações podem ser conferidas em: <https://mapabrasileirodaCovid.inloco.com.br/pt/>
A Ação Direta de Inconstitucionalidade (ADI) 6.341 tomada pelo Superior Tribunal Federal (STF) em 24 de março de 2020 reconheceu que estados e municípios possuem poder para definir regras sobre o distanciamento social o que é interessante do ponto de vista da autonomia quando se trata de municípios em que as populações estão em constante fluxo, como ocorre nas regiões metropolitanas. As regras de distanciamento estão relacionadas à manutenção de serviços essenciais em funcionamento e fechamento da maior parte do comércio em diferentes períodos. A ausência de decisões conjuntas entre os diferentes entes federativos fez com que o índice de isolamento social diminuísse cada vez mais a partir do mês de abril como demonstra a Figura 8.

Figura 8 - Índice de isolamento social no Brasil ao longo do tempo (gráfico) e por estado em 7 de julho de 2020 (mapa).

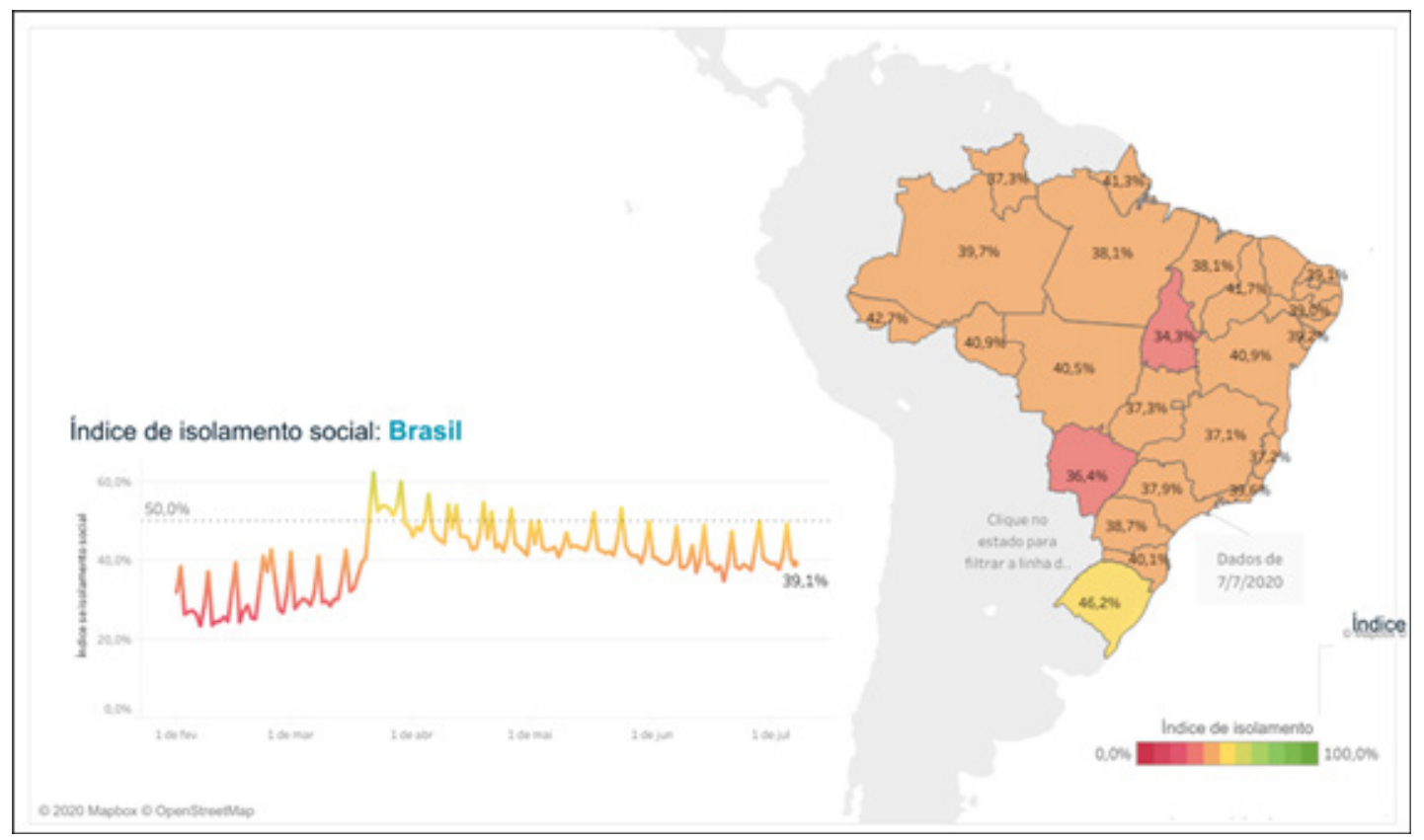

Fonte: In Loco (2020) 
Mesmo com os entraves entre a população, gestores empresariais e gestores administrativos de municípios e estados, o comércio registrou no mês de maio de 2020 um crescimento de $13,9 \%$ com relação a abril do mesmo ano, de acordo com Instituto Brasileiro de Geografia e Estatística (IBGE, 2020). Embora a variação da receita nominal tenha sido $-7,2 \%$ menor que no mesmo mês de 2019, o resultado sinaliza uma recuperação econômica pela demanda existente das populações e suprida pelo comércio local. As redes de transportes locais e regionais (transporte coletivos de passageiros, rodoviários de carga etc.) contribuem para isso, algo que não ocorre, e acredita-se que demorará ocorrer, para o caso do transporte aéreo civil. Esse tipo de transporte, responsável pela circulação de pessoas e bagagens, da entrada do aeroporto de embarque até a saída do aeroporto de desembarque e durante o voo tem diversas medidas a respeito da aglomeração. É necessário distanciamento entre cadeiras nos aeroportos e dentro das aeronaves. Estima-se que a capacidade das aeronaves tenha caído pela metade para atender os critérios de biossegurança. Mesmo assim a demanda caiu vertiginosamente não preenchendo nem mesmo os assentos estimados.

As administradoras $\mathrm{CCR}$ e Triunfo relataram as quedas no fluxo de aeronaves e passageiros em aeroportos sob suas tutelas. Atualmente, a Triunfo é responsável pelo aeroporto de Viracopos, em Campinas, no estado de São Paulo, enquanto a CCR administra os aeroportos de Belo Horizonte, em Minas Gerais, Quito, no Equador, San José, na Costa Rica, e Curaçao nas Antilhas Holandesas. 0 Quadro 01 demonstra o fluxo de aeronaves e passageiros nos aeroportos nacionais de ambas as empresas em 2019 e 2020 em seus primeiros cinco meses.

\begin{tabular}{|c|c|c|c|c|c|c|c|c|}
\hline & \multicolumn{4}{|c|}{$\begin{array}{c}\text { Confins (Belo Horizonte-Minas } \\
\text { Gerais) }\end{array}$} & \multicolumn{3}{c|}{ Viracopos (Campinas-São Paulo) } \\
\hline & Aeronaves & \multicolumn{2}{c|}{ Passageiros } & \multicolumn{2}{c|}{ Aeronaves } & Passageiros \\
\hline Ano & 2019 & 2020 & 2019 & 2020 & 2019 & 2020 & 2019 & 2020 \\
\hline Janeiro & 4.540 & 4.615 & 374.263 & 397.540 & 9.748 & 9.664 & 890.000 & 964.000 \\
\hline Fevereiro & 3.941 & 3955 & 290.345 & 309.380 & 18.836 & 18.758 & 1.685 .000 & 1.803 .000 \\
\hline Março & 4.122 & 2959 & 332.560 & 176.067 & 9.540 & 2.730 & 865.458 & 165.633 \\
\hline Abril & 4.030 & 336 & 328.641 & 11.352 & 9.480 & 2.190 & 846.930 & 138.810 \\
\hline Maio & 4.134 & N/D* & 309.447 & N/D & 9.672 & 2.976 & 896.985 & 226.579 \\
\hline
\end{tabular}

Fonte: CCR (2020); Triunfo (2020). *Não disponível

De 1 de janeiro a 21 de maio de 2020 a CCR registrou queda de fluxo de $39,1 \%$ nos aeroportos sob sua tutela. Especificamente no aeroporto de Confins, entre os meses de janeiro e abril de 2020 houve um decréscimo de $97,14 \%$ do número de passageiros e de $92,71 \%$ do fluxo de aeronaves. A variação percentual do número de passageiros e aeronaves no mês de abril de 2020 em relação a abril de 2019 foi de $-96,54 \%$. Esses percentuais indicam a diminuição do tráfego aéreo pelas medidas impostas devido a pandemia e possui como consequência a diminuição da demanda de voos e assentos.

Em reportagem do jornal Folha de São Paulo (2020), várias empresas pelo mundo relataram ter tomado esse tipo de medida tanto por conta do distanciamento social quanto pela baixa da demanda. Quando comparamos a relação passageiros por aeronaves nota-se no caso de Confins que em abril de 2019 a presença de pelo menos 81 passageiros, o que caiu para 33 no mesmo mês do ano seguinte, e em Viracopos 89 e 63 nos mesmos períodos, respectivamente. Para uma aeronave da empresa Azul, que tem ambos os aeroportos como hubs $^{5}$, como a Embraer E-190 que possui capacidade entre 124 e 108 passageiros (a depender do número de classes) o decréscimo pode representar, àqueles que precisam de fato viajar utilizando o transporte aéreo, a possibilidade do encarecimento das passagens por parte das empresas para tentar recuperar mercado. A pandemia se distribui localmente pelo Brasil de modo distinto, assim como o fluxo de aeronaves, como é possível observar na Figura 10.

5 Hubs: aeroportos com maior número de conexões para outras localidades. 


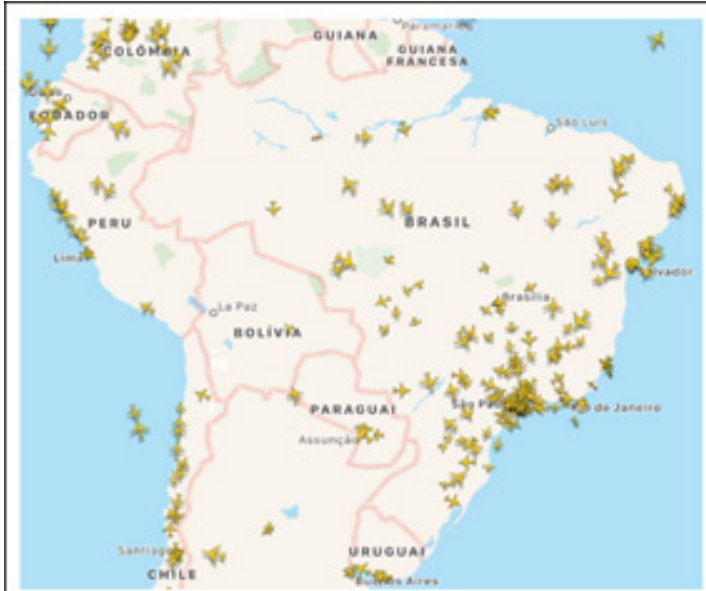

LEGENDA Aviőes no ar rastreados em agosto de 2020

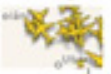

Aviă॰ em movimento

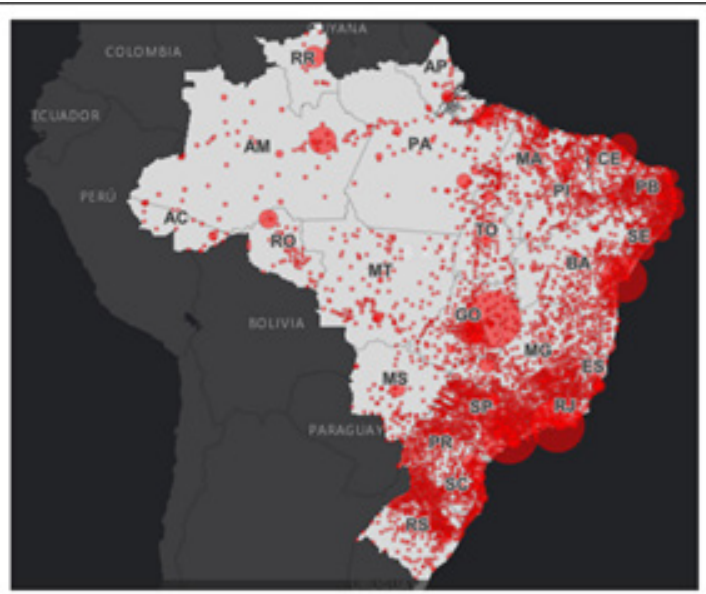

Casos confirmados de Covid-19 (agosto de 2020)

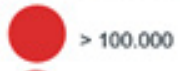

80.000

50.000

- 20.000

$<1$

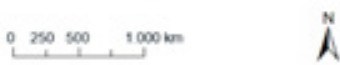

Fonte: Flightradar24 (2020) Universidade Rice University (2020) Elaboração: Denis Castitho

Fonte: FlightRadar24 (2020); Rice University (2020).

Inevitavelmente, a evolução da pandemia possui relação com o modo como as redes de transportes se articulam formando os principais eixos de difusão, como ocorreu no Brasil (CONFINS, 2020). Essa articulação das redes de transportes, como bem evidenciou Oliveira (2020), atinge diferencialmente os lugares, uma vez que acabaram sendo não apenas vetores do fluxo de pessoas e mercadorias, mas também de doenças, como ocorre com a Covid-19. A Figura 11 ilustra muito bem essa relação e revela a cartografia e os principais fluxos da pandemia em escala mundial em dezembro de 2019 e março de 2020, conforme destacado por Castilho (2020).

Figura 11 - Fluxo aéreo mundial e casos confirmados de Covid-19 (2019-2020).

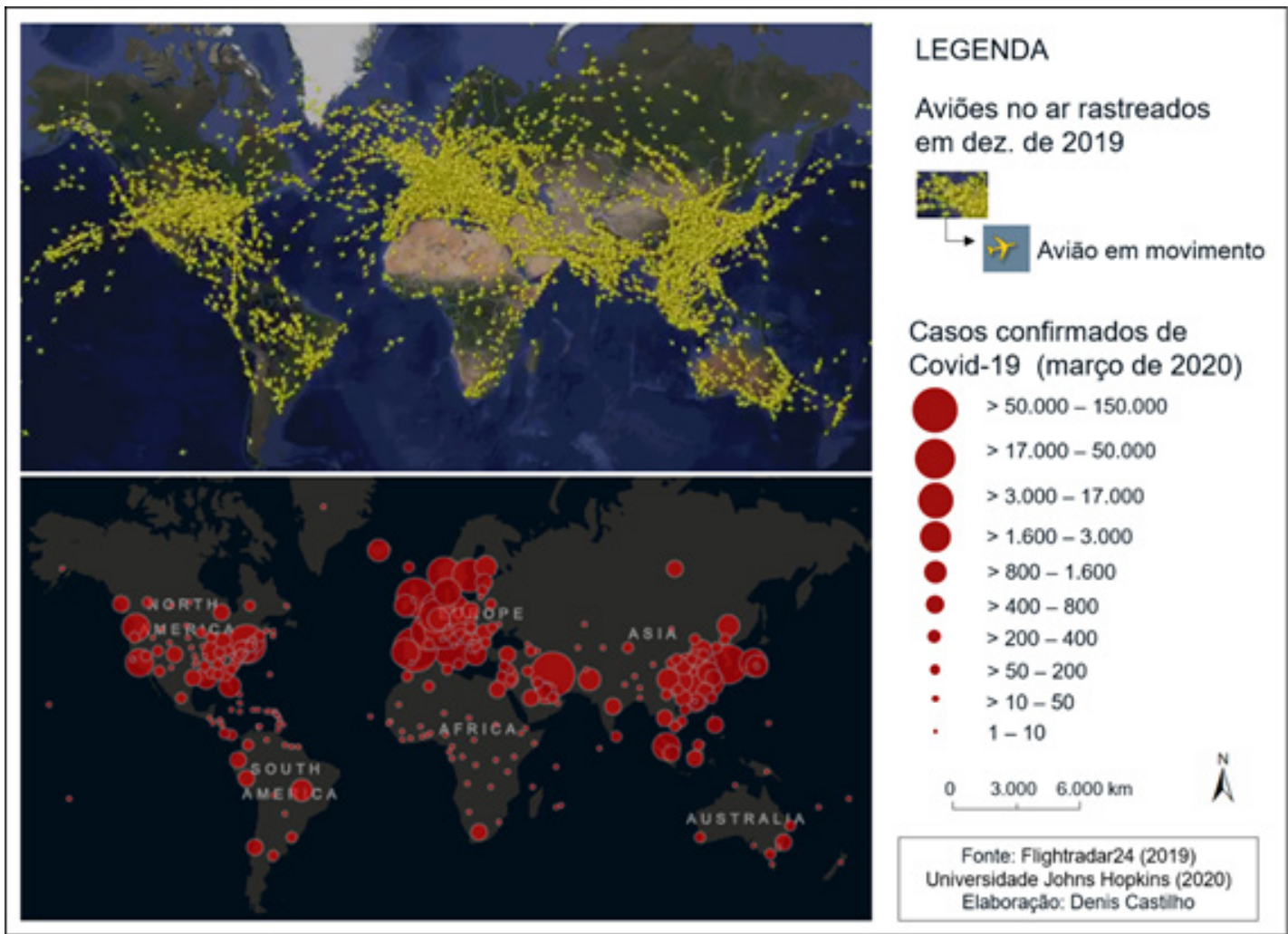

Fonte: FlightRadar24 (2020); Johns Hopkins University (2020). 
Como mostra a figura, a rede de transporte aéreo foi um dos grandes vetores de transmissão da COVID-19 pelo mundo, especialmente nos primeiros meses de 2020 , e por isso tem sido a rede de transporte mais atingida nesse período. Mesmo com a reabertura de fronteiras aéreas pelo mundo, a demanda se mantém baixa principalmente em países tidos como epicentros da pandemia. É o caso do Brasil, que reabriu suas fronteiras para tentar recuperar a economia com relação ao turismo em 30 de julho (EBC, 2020). Com pedidos de remarcação e cancelamentos, pedidos de recuperação judicial e esvaziamento dos aeroportos, há indícios de encarecimento do valor das passagens quando a demanda voltar à normalidade. A previsão de alta, segundo reportagem da revista Exame (2020) e de levantamento junto à Associação Internacional de Transporte Aéreo (IATA), é de $40 \%$ a depender da região do planeta. Importante destacar que, como o espraiamento do vírus possui relação com a estrutura das classes sociais, chegando aos países periféricos, na maior parte dos casos, pela via aérea a partir de viagens de empresários, executivos e políticos, não é demais lembrar que em países como o Brasil o novo coronavírus chegou de avião escancarando um forte caráter de classe. Embora a pandemia tem evidenciado as disparidades nas questões sanitárias, envolvendo facilidades que muitos ricos do país encontram no acesso ao serviço de saúde, como mostra a manchete publicada em 07 de abril de 2020 pelo website UOL "Coronavírus: ricos de Belém escapam em UTI aérea de colapso nos hospitais da cidade", também é revelador o papel do Sistema Único de Saúde (SUS).

O custo de uma UTI aérea partindo de Manaus com destino a São Paulo gira em torno de R\$ 80.000 reais, valor que varia a depender do trecho, equipamentos, profissionais a bordo ou nível de complexidade da doença. Se os ricos de Belém e de Manaus utilizam desses serviços, não é demais notar que o SUS seja um dos principais clientes dessa modalidade de atendimento e alcança comunidades isoladas em muitas áreas da Amazônia. No estado de Mato Grosso, o segundo maior gasto do governo no âmbito da saúde nos meses entre março e junho de 2020 foi de praticamente 10 milhões de reais com UTIs aéreas destinados a uma empresa do setor, de acordo com apuração do Jornal Gazeta Digital.

No ano de 2020 podemos observar com mais veemência a importância e as fragilidades da rede de transporte aéreo com a pandemia. Desde a década de 1950, a máxima do capitalismo foi alinhada a de vários pensadores - produzir e circular - como inclusive foi discutido em algumas partes do presente texto. A mobilidade do vírus se choca com a mobilidade das mercadorias e pessoas. As mercadorias, principalmente as ditas essenciais, como alimentos e medicamentos, continuaram a abastecer os mercados locais majoritariamente sendo transportados pelas rodovias. Os Correios são um testemunho claro desse processo, que até o mês de junho de 2020 teve aumento de $25 \%$ em sua demanda do fluxo de encomendas (FOLHA DE SÃO PAULO, 2020), o que significa que há ressalvas com a pandemia, mas a circulação continua. As redes de comunicação demonstram a força das empresas com a alta do e-commerce e a manutenção das redes de circulação terrestre como aliadas nesses fluxos e processos.

Na obra Epopeia do Correio Aéreo, Souza (1986, p. 108) apresenta um relato sobre a viagem de 1944 de Lysias Augusto Rodrigues, brigadeiro da Aeronáutica Militar, sobre a Rota do Tocantins desbravada nove anos antes pelo próprio. Pousando e decolando sobre diversos municípios do então Norte Goiano, atual estado do Tocantins, há a seguinte passagem:

\footnotetext{
Aterramos no "tapete" da cidade de Peixe e, 30 minutos depois, estávamos aterrando em Palma [atual município de Paranã]. Palestrei com o doutor Guintiliano Silva, que é o médico chefe do posto de saúde desta pequenina cidade, na qual é ele residente há quinze anos. Disse-me que a maior dificuldade que lá existia era de comunicações e que isso o CAN [Correio Aéreo Nacional, anteriormente Correio Aéreo Militar] viera resolver, pois que uma carta levava para lá chegar seis meses, o Correio Aéreo entrega no mesmo dia. Contou-me o caso de uma moça que necessitava de tomar um soro e que o CAN levou no dia seguinte, tendo-a salvo desta forma. Disse-me que a ação do CAN "era sobretudo humanitária" pois que atendia a zone pobre do Brasil. (SOUZA, 1986, p. 108)
}

Essa passagem revela algumas nuances do papel que a aviação tem para as localidades distantes dos grandes centros econômicos. Nota-se o papel do Correio Aéreo Nacional (CAN) de promover a circulação de bagagens e encomendas, e de servir como recurso para $o$ atendimento em outras localidades dotadas de equipamentos de saúde. Nota-se também a agilidade para que as demandas cheguem nessas localidades.

O paralelo das UTIs aéreas, e até mesmo dos Correios, revela a importância e um certo anacronismo do Estado enquanto articulador dos fluxos direcionados às demandas sociais. Em momentos como o atual, em que grandes companhias aéreas de vários países acionam recursos suntuosos do Estado, as agendas sanitária e social não podem deixar de pautar o debate e a luta em torno do necessário fortalecimento e ampliação de serviços que sejam verdadeiramente públicos e 
universalizados.

\section{Considerações finais}

O movimento da pandemia e as transformações por ele desencadeadas tem se tornado um desafio às instituições, à ciência e à nossa capacidade de entender a rapidez das mudanças. Embora muitas novidades estejam emergindo com o vírus, ele não deixa de carregar a insígnia de nosso tempo, das redes e dos lugares por onde tem sido disseminado de maneira tão rápida e, ao mesmo tempo, tão dramática. É um vírus que escancara as contradições de um tipo de sociedade que gestou a pandemia, mas que se mostra profundamente incapaz de enfrentá-la, como tem evidenciado Santos (2020).

0 vírus, nesse sentido, tem sido didático ao revelar a estrutura degradante dos sistemas corporativos e o modo como os principais fluxos da economia globalizada são produzidos e controlados. Do ponto de vista dos protocolos de biossegurança, é importante citar que boa parte das atuais restrições na circulação de pessoas foram tomadas a partir do atentado às Torres Gêmeas do World Trade Center, em Nova Iorque, em 11 de setembro de 2001. É possível que tenhamos que conviver também com vários protocolos sanitários delineados a partir da pandemia da Covid-19, muitas das quais estarão compondo, em um futuro próximo, sistemas de vigilância, de controle e de cerceamento ainda mais radicais.

Empresas de transporte aéreo em diversos países têm iniciado um plano de reestruturações considerando as restrições e as novas medidas sanitárias. Parte essencial dessa retomada apenas reforça uma receita antiga: o Estado e o acesso privilegiado a seus recursos e ativos. 0 governo alemão, por exemplo, planeja estatizar temporariamente a Lufthansa, adquirindo $25 \%$ de seus ativos, até que se recupere a companhia, de acordo com o jornal Deutsche Welle (2020). As implicações da pandemia na circulação e nos fluxos colocam em questão velhas formas de organização das companhias aéreas, mas reforça sua dependência às ações do Estado e aos recursos públicos. Isso significa que a pandemia e a crise econômica por ela agravada evidenciam ainda mais as redes como vetores de espoliação e de pilhagem, como discutido por Castilho (2019).

No que tange ao modo como a pandemia alcança diferentemente os lugares, não é demais lembrar que as condições de acesso à saúde guardam um drama peculiar no Brasil. 0 acesso à serviços de saúde de alguém que mora em bairro nobre de São Paulo é bem diferente de um habitante pobre de São Gabriel da Cachoeira, no Amazonas. A geografia do drama também mostra que o slogan "fique em casa" ou "lave as mãos" não faz sentido à muitas pessoas em situação de rua ou que não são assistidas por serviços que lhes são de direito. A pandemia também ensina, enfim, que nunca fomos iguais, a não ser pela dor. 


\section{Referências}

ANAC (Agência Nacional de Aviação Civil). 2020. Informações sobre o Mercado do Transporte Aéreo (2019-2020). Disponível em: <https://www.anac.gov.br/assuntos/dados-e-estatisticas/mercado-do-transporte-aereo>. Acesso: em 05 jul. 2020.

Informações para a sua viagem durante a Covid-19. 2020. Disponível em: <https://www.anac.gov.br/coronavirus/ veja-tambem/guia-passageiros-Covid.pdf>. Acesso: em 05 jul. 2020.

BRASIL, Superior Tribunal Federal. 2020. Medida cautelar na Ação Direta de Inconstitucionalidade 6.431, que atribuiu à Presidência da República a centralização das prerrogativas de isolamento, quarentena, interdição de locomoção e de serviços públicos e atividades essenciais, 24/03/2020. Acesso em: 18 mai. 2020. Disponível em: <http://www.stf.jus. $\mathrm{br} /$ arquivo/cms/noticiaNoticiaStf/anexo/ADI6341.pdf>.

BRASIL, Empresa Brasileira de Comunicação. 2020. Governo autoriza reabertura de fronteiras aéreas para entrada de estrangeiros no Brasil. Empresa Brasileira de Comunicação, 30/07/2020. Disponível em: <https://radioagencianacional. ebc.com.br/politica/audio/2020-07/governo-autoriza-reabertura-de-fronteiras-aereas-para-entrada-de-estrangeiros>. Acesso em: 06 ago. 2020.

COTA, W. 2020. Monitoring the number of COVID-19 cases and deaths in Brazil at municipal and federative units' level. SciELO Preprints, Health Sciences.

BH AIRPORT. 2020. Estatísticas e publicações. Disponível em: <https://www.bh-airport.com.br/SitePages/pt/ publicacoes/estatisticas.aspx>. Acesso em 20 jun. 2020.

CARLOS, A. F. A. 1996. O lugar no/do mundo. São Paulo: Hucitec.

CASTILHO, D. 2019. Redes e processos espoliativos no centro-norte do Brasil. In: OLIVEIRA, F. G. de; OLIVEIRA, L. D. de; TUNES, R. H.; PESSANHA, R. M. (orgs.). Espaço e Economia: Geografia econômica e a economia política. Rio de Janeiro: Contexto, p. 295-320.

CASTILHO, D. 2020. Um vírus com DNA da Globalização: e espectro da perversidade. Espaço e Economia, número 17, 2020. Disponível em: <https://journals.openedition.org/espacoeconomia/10332/>. Acesso em: 15 ago. 2020.

CONFINS. Como o coronavírus viaja pelo Brasil, três casos exemplares. Confins, número 45, 2020. Disponível em $<$ http://journals.openedition.org/confins/28436> Acesso em: 15 ago. 2020.

COSTA, J. M.; UEDA, V. 2007. Redes e Territórios: notas sobre a reticulação espacial. Boletim Gaúcho de Geografia, 32 : 131-145.

DISTRITO FEDERAL, Agência Brasília. 2020. DER-DF registra queda de $45 \%$ no número de veículos nas rodovias. Agência Brasília. Disponível em: <https://www.agenciabrasilia.df.gov.br/2020/05/18/der-df-registra-queda-de-45-no-numero-deveiculos-nas-rodovias/>. Acesso em: 20 mai. 2020.

DEUTSCHE WELLE. 2020. Alemanha planeja estatizar parte da Lufthansa. Deutsche Welle, 21/05/2020. Disponível em: $<$ https://p.dw.com/p/3caAl>. Acesso em 06 jun. 2020.

EPOCA. 2020. Coronavírus: ricos de Belém escapam em UTI aérea de colapso nos hospitais da cidade. Época, 06/05/2020. Disponível em: <https://epoca.globo.com/sociedade/coronavirus-ricos-de-belem-escapam-em-uti-aereade-colapso-nos-hospitais-da-cidade-1-24412850>. Acesso em: 22 jun. 2020.

ESTADÃO. 2020. Agro aquece mercado de caminhões. Estadão, São Paulo, 26/05/2020. Disponível em: <https:// mobilidade.estadao.com.br/mobilidade-para-que/agro-aquece-mercado-de-caminhoes/>. Acesso em: 19 jun. 2020.

2020. Nesse momento é importante que haja benefícios fiscais nunca vistos na história, diz Benchimol. Estadão, São Paulo 05/05/2020. Disponível em: <https://economia.estadao.com.br/noticias/geral,nesse-momento-e-importanteque-haja-beneficios-fiscais-nunca-vistos-na-historia-diz-benchimol,70003293050>. Acesso em: 05 jul. 2020.

2020. Recuperação judicial de empresas aéreas pode prejudicar retomada da América Latina. Estadão,

09/06/2020. Disponível em: <https://economia.estadao.com.br/noticias/geral,recuperacao-judicial-de-empresasaereas-pode-prejudicar-retomada-da-america-latina-diz-iata,70003329306>. Acesso em 22 jul. 2020.

EUROCONTROL. 2020 Supporting European Aviation. Disponível em: <https://www.eurocontrol.int/>. Acesso em: 03 jun. 2020.

EXAME. 2020. Com redução de assentos, preços das passagens aéreas podem subir até 54\%. Exame, 12/05/2020. Disponível em: <https://exame.com/seu-dinheiro/com-reducao-de-assentos-precos-das-passagens-aereas-podemsubir-ate-54/>. Acesso em: 03 ago. 2020.

FOLHA DE SÃO PAULO. 2020. Brasil tem recorde de casos diários de Covid-19. Folha de São Paulo, 22/05/2020. Disponível em: <https://www1.folha.uol.com.br/equilibrioesaude/2020/07/brasil-tem-recorde-de-casos-diarios-de- 
Covid-19-mais-de-65-mil.shtml>. Acesso em: 22/07/2020.

2020. Companhias aéreas têm custo milionário com aviões em solo por coronavírus. Folha de São Paulo, 20/04/2020. Disponível em: <https://www1.folha.uol.com.br/mercado/2020/04/companhias-aereas-tem-customilionario-com-avioes-em-solo-por-coronavirus.shtml>. Acesso em: 15 mai. 2020.

.2020. Redução de assentos e reforço na limpeza devem impactar preço de passagem aérea. Folha de São Paulo, 04/05/2020. Disponível em: <https://www1.folha.uol.com.br/turismo/2020/05/reducao-de-assentos-e-reforco-nalimpeza-devem-impactar-preco-de-passagem-aerea.shtml>. Acesso em 05 jul. 2020.

2020. Demanda dos Correios cresce $25 \%$ na pandemia impulsionada por ecommerce. Folha de São Paulo, 25/07/2020. Disponível em: <https://www1.folha.uol.com.br/mercado/2020/07/demanda-dos-correios-cresce-25-napandemia-impulsionada-por-ecommerce.shtml>. Acesso em 10 ago. 2020.

G1. 2020. Veículos de comunicação formam parceria para dar transparência a dados de Covid-19. G1, 08/06/2020. Disponível em: <https://g1.globo.com/politica/noticia/2020/06/08/veiculos-de-comunicacao-formam-parceria-paradar-transparencia-a-dados-de-covid-19.ghtml>. Acesso em: 10 set. 2020.

G1 DISTRITO FEDERAL. 2020. Após 105 dias, primeira paciente diagnosticada com Covid-19 no DF recebe alta e vai para casa. G1 Distrito Federal, Brasília, 16/06/2020. Disponível em: <https://g1.globo.com/df/distrito-federal/ noticia/2020/06/16/apos-105-dias-primeira-paciente-diagnosticada-com-Covid-19-no-df-recebe-alta-e-vai-para-casa. ghtml>. Acesso em: 01 jul. 2020.

G1 GOIÁS. 2020. Goiás tem três casos confirmados de coronavirus, diz governo. G1 Goiás, 12/03/2020. Disponível em: <https://g1.globo.com/go/goias/noticia/2020/03/12/goias-tem-tres-casos-confirmados-de-coronavirus-diz-governo. ghtml>. Acesso em: 15 jun. 2020.

GRUPO CCR. 2020. Relatórios a Comissão de Valores Mobiliários. Disponível em: <http://ri.ccr.com.br/divulgacao-eresultados/relatorios-cvm/>. Acesso em: 30 jun. 2020.

GAZETA DIGITAL. Aumento nos casos de covid-19 faz governo aumentar gastos com saúde. Gazeta Digital, 15/07/2020. Disponível em: < https://www.gazetadigital.com.br/editorias/politica-de-mt/aumento-nos-casos-de-covid-19-fazgoverno-aumentar-gastos-com-sade/622601>. Acesso em: 06 ago. 2020.

HARARI, Y. N. 2020. In the Battle Against Coronavirus, Humanity Lacks Leadership. TIME, 15/03/2020. Disponível em: <https://time.com/5803225/yuval-noah-harari-coronavirus-humanity-leadership/>. Acesso em: 15 mai. 2020.

HOLTZ, Fabiana. Recuperação judicial de empresas aéreas pode prejudicar retomada da América Latina. Estado de São Paulo, 9 jun. 2020.

IBGE (Instituto Brasileiro de Geografia e Estatística). 2020. PMC - Pesquisa Mensal do Comércio. Disponível em: <https:// www.ibge.gov.br/estatisticas/economicas/comercio/9227-pesquisa-mensal-de-comercio.html?=\&t=destaques>

Acesso em: 03/07/2020.

2019. IBGE divulga as estimativas da população dos municípios para 2019. Agência IBGE Notícias, 28/04/2019. Disponível em: <encurtador.com.br/cKRWY>. Acesso em: 02 jul. 2020.

ICAO (International Civil Aviation Organization). 2020. Effects of Novel Coronavirus (COVID-19) on Civil Aviation: Economic Impact Analysis. Disponível em: <http://capsca.org/Documentation/CoronaVirus/ICAO\%20Coronavirus\%202020\%20 03\%2013\%20Econ\%20Impact.pdf>. Acesso em: 11 jul. 2020.

2020. Global Covid-19 Airport Status. Disponível em: <https://www.icao.int/safety/Pages/COVID-19-AirportStatus.aspx>. Acesso em: 11 jul. 2020.

INVEPAR (Investimentos e Participações em Infraestrutura S.A.). 2020. Desempenho dos negócios: fluxos aeroportuários, rodoviários e de mobilidade urbana. Disponível em: <https://mz-prod-cvm.s3.amazonaws.com/18775/IPE/2020/ d2f7e64c-2c57-41ca-916c-e2758ee3c074/20200616113632664263_18775_769344.pdf>. Acesso em 02 jul. 2020.

INLOCO. 2020. Nota de atualização do Índice de Isolamento Social. Disponível em: <encurtador.com.br/orMY5>. Acesso em 20 jun. 2020.

OLIVEIRA, L. D. 2020. Para além da capital - os eixos geográficos de dispersão da pandemia de Covid-19 no estado do Rio de Janeiro. PPGIHD-UFRRJ. 21/03/2020. Disponível em: <https://bit.ly/3bJRpfe>. Acesso em: 20 jul. 2020.

OMS/WHO (Organização Mundial da Saúde/World Health Organization). 2020. WHO Timeline - Covid-19. Disponível em: <https://www.who.int/news-room/detail/27-04-2020-who-timeline---Covid-19>. Acesso em: 19 mai. 2020.

PARENTE, A. 2007. Rede e subjetividade na filosofia francesa contemporânea. Revista Eletrônica de Comunicação, Informação e Inovação em Saúde, v. 1, n. 1, p. 101-105.

RAFFESTIN, C. 1993. Por uma geografia do poder. São Paulo: Ática.

ROSER, M (et al). 2020. Coronavirus Pandemic (COVID-19). Disponível em <https://ourworldindata.org/coronavirus>. 
Acesso em: 20 mai. 2020.

SANTOS, B. A cruel pedagogia do vírus. Coimbra: Edições Almedina, 2020.

SANTOS, M. 1997. Técnica, espaço, tempo: globalização e meio técnico-científico informacional. São Paulo: Edusp. 2006. A natureza do espaço: técnica e tempo, razão e emoção. 4 ed. São Paulo: Edusp.

1988. Metamorfoses do espaço habitado. São Paulo: Hucitec, v. 4, p. 136.

SILVA JUNIOR, R. F. 2007. A circulação como um dos fundamentos do espaço: elementos para a busca de um conceito. Geografia e Pesquisa, v. 1, n. 1, p. $139-155$.

SILVEIRA, R.L.L. 2003. Redes e território: uma breve contribuição geográfica ao debate sobre a relação sociedade e tecnologia. Revista Bibliográfica de Geografía y Ciencias Sociales, Barcelona, v. 8, n. 451.

TRIUNFO CONCEBRA. 2020. Rodovias sob concessão. Disponível em: <https://www.triunfo.com/a-companhia/ empresas-triunfo/rodovias/triunfo-concebra/>. Acesso em: 16 jun. 2020.

UFRGS (Universidade Federal do Rio Grande do Sul). 2020. Qual a diferença de distanciamento social, isolamento e quarentena? Disponível em: <https://www.ufrgs.br/telessauders/posts_coronavirus/qual-a-diferenca-dedistanciamento-social-isolamento-e-quarentena/>. Acesso em: 25 jul. 2020.

WILDER-SMITH, A.; FREEDMAN, D.O. 2020. Isolation, quarantine, social distancing, and community containment: pivotal role for old-style public health measures in the novel coronavirus (2019-nCoV) outbreak. Journal of Travel Medicine, Volume 27, Issue 2. Disponível em: <https://academic.oup.com/jtm/article/27/2/taaa020/5735321>. Acesso em: 15 jul. 2020. 